\title{
Left ventricular mass regression, all-cause and cardiovascular mortality in chronic kidney disease: a meta-analysis
}

Kevin C. Maki ${ }^{1,2^{*}}$, Meredith L. Wilcox², Mary R. Dicklin², Rahul Kakkar ${ }^{3}$ and Michael H. Davidson ${ }^{4}$

\begin{abstract}
Background: Cardiovascular disease is an important driver of the increased mortality associated with chronic kidney disease (CKD). Higher left ventricular mass (LVM) predicts increased risk of adverse cardiovascular outcomes and total mortality, but previous reviews have shown no clear association between intervention-induced LVM change and allcause or cardiovascular mortality in CKD.

Methods: The primary objective of this meta-analysis was to investigate whether treatment-induced reductions in LVM over periods $\geq 12$ months were associated with all-cause mortality in patients with CKD. Cardiovascular mortality was investigated as a secondary outcome. Measures of association in the form of relative risks (RRs) with associated variability and precision (95\% confidence intervals [Cls]) were extracted directly from each study, when reported, or were calculated based on the published data, if possible, and pooled RR estimates were determined.

Results: The meta-analysis included 42 trials with duration $\geq 12$ months: 6 of erythropoietin stimulating agents treating to higher vs. lower hemoglobin targets, 10 of renin-angiotensin-aldosterone system inhibitors vs. placebo or another blood pressure lowering agent, 14 of modified hemodialysis regimens, and 12 of other types of interventions. All-cause mortality was reported in 121/2584 (4.86\%) subjects in intervention groups and 168/2606 (6.45\%) subjects in control groups. The pooled RR estimate of the 27 trials $\geq 12$ months with $\geq 1$ event in $\geq 1$ group was $0.72(95 \% \mathrm{Cl}$ 0.57 to $0.90, p=0.005$ ), with little heterogeneity across studies. Directionalities of the associations in intervention subgroups were the same. Sensitivity analyses of $\geq 6$ months ( 34 trials), $\geq 9$ months ( 29 trials), and $>12$ months ( 10 trials), and including studies with no events in either group, demonstrated similar risk reductions to the primary analysis. The point estimate for cardiovascular mortality was similar to all-cause mortality, but not statistically significant: RR 0.67, 95\% Cl 0.39 to 1.16 .
\end{abstract}

Conclusions: These results suggest that LVM regression may be a useful surrogate marker for benefits of interventions intended to reduce mortality risk in patients with CKD.

Keywords: Chronic kidney disease, Cardiovascular disease, Left ventricular mass index, Mortality

*Correspondence: kcmaki@iu.edu

1 Department of Applied Health Science, Indiana University School of Public Health, 1025 E 7th St \#111, Bloomington, IN 47405, USA Full list of author information is available at the end of the article

\begin{abstract}
Background
Chronic kidney disease (CKD) is a major public health issue, with an estimated global prevalence of $13.4 \%$ (broadly ranging from approximately 5 to $15 \%$ across the world); approximately 5-7 million persons worldwide have end-stage kidney disease (ESKD) requiring dialysis, and, ultimately, renal replacement therapy [1].
\end{abstract}


Mortality is increased in patients with CKD compared to those without CKD, and an important driver of mortality is increased risk for cardiovascular disease (CVD) $[2,3]$. Left ventricular hypertrophy $(\mathrm{LVH})$ is present in $15-21 \%$ of the general population, but affects $50-70 \%$ of patients with CKD, and as many as $80 \%$ of patients with CKD on dialysis [4-8]. LVH is a marker for the hemodynamic (afterload and preload) and non-hemodynamic (humoral, endocrine, autonomic and cellular) changes that impact the myocardium in CKD. Higher left ventricular mass (LVM) or left ventricular mass index (LVMI) predicts increased risk of adverse cardiovascular outcomes and total mortality in several patient populations [9-16], including ESKD patients [17-20]. The investigators of a previous systematic review and meta-regression analysis of 73 randomized controlled trials (RCTs) that investigated the validity of LVM regression as a surrogate endpoint for all-cause and cardiovascular mortality in CKD concluded that there was no clear or consistent association between intervention induced LVM change and mortality [21]. However, a majority of the interventions evaluated in the included trials had little or no effect on LVM, and some actually produced an increase. Moreover, the analysis included studies with durations as short as 3 months, which may not be a sufficient time for benefits to become apparent [10]. The primary objective of the present meta-analysis was to address the question of whether treatment-induced reductions in LVM were associated with all-cause mortality in patients with CKD over periods $\geq 12$ months. Cardiovascular mortality was evaluated as a secondary outcome.

\section{Methods}

This investigation was performed in accordance with the recommendations of the Preferred Reporting Items for Systematic Reviews and Meta-Analyses: The PRISMA Statement [22] and the Methodological Standards for Meta-Analyses and Qualitative Systematic Review of Cardiac Prevention and Treatment Studies: A Scientific Statement from the American Heart Association [23]. The meta-analysis protocol was registered with the international prospective register of systematic reviews (PROSPERO registration number CRD42018106425).

The aforementioned systematic review and metaanalysis publication by Badve et al. included a list of the characteristics and outcomes of studies that had been evaluated for possible inclusion [21]. That list of studies was re-evaluated for possible inclusion in the present meta-analysis and an additional literature search was conducted using the PubMed database, to search for other qualifying papers, particularly those published since the cutpoint specified by Badve et al. (December 2015) through December 2020. The search criteria included: 1) randomized trials that reported treatment effects on LVM in adults or children with any stage of CKD; and 2) randomized trials that reported treatment effects on LVM in adults or children in the general population that included a separate subgroup analysis of participants with CKD. The study exclusion criteria included: 1) observational studies; 2) trials with followup duration <6 months; and 3) trials involving kidney transplant recipients. The search terms used are listed in Supplemental Table 1. The literature search was updated and expanded to other search engines in October 2021 by searching the Cochrane Central Register of Controlled Trials for articles published from 2015-2021 that met the search criteria.

Because the objective of the present analysis was to address the question of whether treatment-induced reductions in LVM were associated with all-cause and cardiovascular mortality in patients with CKD, the primary analysis of the study was further limited to studies in which the intervention had a regressive effect on LVM. Specifically, the primary analysis included studies in which the mean change in standardized LVM (usually expressed as LVMI) was $\leq-0.01$ standard deviations (SD) for the intervention group change minus the control group change. The primary analysis was also limited to studies that followed subjects for a period adequate to collect mortality events, i.e., $\geq 12$ months. This threshold was chosen because the echocardiographic sub-study results from the Losartan Intervention for Endpoint Reduction in Hypertension (LIFE) trial did not show clear evidence of separation between treatments during the first several months [10]. Results are also reported for other follow-up time frames in sensitivity analyses. In cases where multiple secondary publications of the same data set were identified, the publication with the most complete data was used, and additional data from secondary sources were extracted. Also, only data from the first phase of randomized crossover trials were eligible.

Qualitative information and quantitative data were extracted from each publication meeting the inclusion criteria. All data from eligible trials were abstracted by an independent scientist and reviewed by the lead investigator (KCM). Any discrepancies were resolved by discussion with an additional scientist and by referencing the original publication.

Measures of association in the form of relative risks (RRs) with associated variability and precision (95\% confidence intervals [CIs]) were extracted directly from each study, when reported, or were calculated based on the published data, if possible. Pooled RR estimates for the meta-analysis were completed using Comprehensive Meta-Analysis, Version 3 (Biostat, Englewood, NJ). When a study had 0 events in 1 group, the software 
added 0.5 to the number of events and non-events for each group for computation of the log risk ratio and its variance. Statistical significance for individual studies and for pooled RRs was declared when the 95\% CI did not include the null value of 1.0 (i.e., p-value $<0.05$ ). Studies were weighted according to the inverse of the variance of each study's effect using random effects models. Statistical heterogeneity was assessed using Cochran's Q and the $\mathrm{I}^{2}$ statistic. The Cochrane Handbook defines an $\mathrm{I}^{2}$ value of 0 to $40 \%$ as low heterogeneity, which "might not be important" [24]. An $\mathrm{I}^{2}$ value of $\geq 40 \%$ was used to designate moderate or higher heterogeneity. Comprehensive Meta-Analysis uses the inverse variance method for calculating the weighted pooled RR under the fixed effect models, which were considered secondary [25].

The primary outcome variable was RR for all-cause mortality between intervention and control groups for trials with $\geq 12$ months of treatment in which any reduction in mean LVM was reported (whether or not statistically significant in each individual trial). Thus, the exposure of interest was not the treatment applied, but rather the presence of treatment induced LVM regression relative to the control condition. RR for cardiovascular mortality was similarly evaluated as a secondary outcome. Sensitivity analyses were conducted to assess minimum follow-up thresholds of $\geq 6, \geq 9$, and $>12$ months. Sensitivity analyses were also conducted including studies in which 0 events were observed in both comparison groups (by summing totals as if all subjects were in the same trial) to illustrate the degree to which such "no event" trials may have influenced the results. Subgroup analyses by type of intervention (erythropoietin stimulating agent [ESA], renin-angiotensin-aldosterone system inhibitor [RAASi], non-conventional hemodialysis [NCHD], and other), according to LVM or LVMI change $>$ or $\leq$ the median, according to whether the studies enrolled adults only or may have also enrolled children, and according to whether the studies exclusively (or predominantly) enrolled patients with ESKD or did not include patients with ESKD, were also completed for allcause mortality.

A post-hoc random effects meta-regression was performed to investigate the effect of mean change in standardized LVM on the effect size for all-cause mortality and for cardiovascular mortality. Regression coefficients and the percentage of between-study heterogeneity explained by the mean change in standardized LVM $\left(\mathrm{R}^{2}\right.$ ) were generated using Comprehensive Meta-Analysis, Version 3 (Biostat, Englewood, NJ). The random effects variance components of the models were computed using method of moments. Sensitivity analyses were also completed using maximum likelihood and restricted maximum likelihood, which did not alter the results materially.
The presence of publication bias was assessed visually by examining funnel plots measuring the standard error as a function of effect size, as well as statistically by using Egger's regression method [26, 27]. Study quality was assessed using the Grading of Recommendations Assessment, Development and Evaluation (GRADE) method [28].

\section{Results}

A description of the results of the literature search and study screening is shown in Supplemental Fig. 1. A total of 58 studies met the overall inclusion criteria (described in detail in Supplemental Table 2) [29-86]. As shown in Table 1, 42 studies met the inclusion criteria for the primary evaluation of the effects of LVM regression on all-cause mortality with $\geq 12$ months of follow-up. This included 6 studies using ESAs to treat to a higher vs. lower hemoglobin target [37, 38, 43-46], 10 studies of RAASi vs. placebo or vs. another blood pressure-lowering agent $[29,34-36,40,47,49,53,54,70], 14$ studies of more intensive vs. less intensive hemodialysis (greater frequency or vs. high-flux hemodialysis or more intensive fluid management) [30, 48, 51, 56, 57, 61, 64, 67, 68, 72, $74,76,78,82]$, and 12 studies of other types of interventions [31, 33, 52, 62, 66, 75, 77, 79, 83-86]. A total of 30 studies enrolled predominantly ESKD patients (defined as patients on hemodialysis) [29-31, 35, 36, 38, 40, 48, 49, $51,54,56,57,61,64,67,68,70,72,74-79,82-86]$ and 12 studies did not enroll patients on dialysis [33, 34, 37, $43-47,52,53,62,66]$.

A total of 289 deaths were reported in 27 of the 42 qualifying trials: $121 / 2584(4.86 \%)$ subjects in the intervention groups and 168/2606 (6.45\%) subjects in the control groups (Table 1). The pooled RR (95\% CI) estimate from the primary analysis (all-cause mortality in patients with CKD in trials of at least 12 months follow-up in which LVM was reduced in the intervention group relative to the control group and there was at least 1 event in 1 group) was 0.72 ( 0.57 to $0.90, p=0.005$ ) (Table 2 and Fig. 1 ). There was little heterogeneity across studies $\left(\mathrm{I}^{2}=0.0 \%\right.$, $\mathrm{Q}=18.6$, $\mathrm{p}$ for heterogeneity $=0.851$ ). Findings from the sensitivity analysis to evaluate the degree to which exclusion of trials for which no mortality events were reported may have affected the results were not materially different; $\mathrm{RR}=0.73$ ( $95 \%$ CI 0.58 to $0.91, p=0.006$ ). Results of the sensitivity analyses for the pooled RR of all-cause mortality using different thresholds of minimum followup time are shown in Table 3. The pooled RR for studies with $>12$ months follow-up showed $47 \%$ lower cumulative mortality incidence. All timeframes for minimum follow-up thresholds had $95 \%$ CIs that did not cross the null value. The median reductions in LVM in the intervention groups compared with the control groups in the 
Table 1 Trials of $\geq 12$ months follow-up in patients with chronic kidney disease in which left ventricular mass was reduced in the intervention group relative to the control group ${ }^{2}$

\begin{tabular}{|c|c|c|c|c|c|c|c|}
\hline \multirow[t]{2}{*}{ Author, Year } & \multirow[t]{2}{*}{ Intervention } & \multicolumn{2}{|c|}{ Intervention } & \multicolumn{2}{|l|}{ Control } & \multirow{2}{*}{$\begin{array}{l}\mathrm{F} / \mathrm{U} \\
\text { months }\end{array}$} & \multirow{2}{*}{$\begin{array}{l}\operatorname{LVM} \Delta \\
\text { SMD }\end{array}$} \\
\hline & & Events & Subjects & Events & Subjects & & \\
\hline Levin, 2005 [37] & ESA/higher vs. lower hemoglobin target & 1 & 85 & 3 & 87 & 24 & -0.20 \\
\hline Parfrey, 2005 [38] & ESA/higher vs. lower hemoglobin target & 13 & 296 & 20 & 300 & 24 & -0.12 \\
\hline Macdougall, 2007 [43] & ESA/higher vs. lower hemoglobin target & 1 & 65 & 6 & 132 & 36 & -0.25 \\
\hline Ritz, 2007 [44] & ESA/higher vs. lower hemoglobin target & 0 & 89 & 0 & 83 & 15 & -0.05 \\
\hline Pappas, 2008 [46] & ESA/higher vs. lower hemoglobin target & 1 & 15 & 3 & 16 & 12 & -0.97 \\
\hline Cianciaruso, 2008 [45] & ESA/higher vs. lower hemoglobin target & 1 & 46 & 0 & 49 & 24 & -0.07 \\
\hline \multirow[t]{5}{*}{ Suzuki, 2002 [34] } & RAASi vs. placebo or standard treatment & & & & & & \\
\hline & without LVH, $5 \mathrm{mg}$ benazepril & 0 & 12 & 0 & 12 & 12 & -0.52 \\
\hline & without LVH, $2.5 \mathrm{mg}$ benazepril & 0 & 12 & 0 & 12 & 12 & -0.43 \\
\hline & with LVH, 5 mg benazepril & 0 & 12 & 0 & 12 & 12 & -0.44 \\
\hline & with LVH, $2.5 \mathrm{mg}$ benazepril & 0 & 12 & 0 & 12 & 12 & -0.15 \\
\hline London, 1994 [29] & RAASi vs. placebo or standard treatment & 0 & 16 & 0 & 16 & 12 & -0.57 \\
\hline Suzuki, 2003 [35] & RAASi vs. placebo or standard treatment & 0 & 14 & 0 & 10 & 12 & -0.61 \\
\hline Kanno, 2004 [36] & RAASi vs. placebo or standard treatment & 0 & 12 & 0 & 12 & 12 & -1.05 \\
\hline$Y u, 2006[40]$ & RAASi vs. placebo or standard treatment & 1 & 24 & 0 & 22 & 12 & -0.51 \\
\hline Mitsuhashi, 2009 [49] & RAASi vs. placebo or standard treatment & 0 & 20 & 0 & 20 & 12 & -0.89 \\
\hline Zeltner, 2008 [47] & RAASi vs. placebo or standard treatment & 0 & 23 & 0 & 23 & 36 & -0.01 \\
\hline Yilmaz, 2010 [54] & RAASi vs. placebo or standard treatment & 0 & 56 & 1 & 56 & 12 & -0.18 \\
\hline Ito, 2014 [70] & RAASi vs. placebo or standard treatment & 2 & 78 & 5 & 80 & 24 & -0.34 \\
\hline Ulusoy, 2010 [53] & RAASi vs. other RAASi & 0 & 19 & 0 & 13 & 12 & -0.49 \\
\hline Schrander-vd Meer, 1999 [30] & Convective HD vs. standard HD & 0 & 12 & 0 & 12 & 12 & -0.69 \\
\hline Alvestrand, 2011 [56] & Convective HD vs. standard HD & 2 & 27 & 3 & 21 & 24 & -0.31 \\
\hline Ohtake, 2012 [64] & Convective HD vs. standard HD & 0 & 13 & 0 & 9 & 12 & -0.26 \\
\hline Mostovaya, 2014 [72] & Convective HD vs. standard HD & 41 & 358 & 51 & 356 & 12 & -0.11 \\
\hline Katopodis, 2009 [48] & $\geq 4 \times$ vs. $<4 x /$ week HD & 0 & 9 & 0 & 9 & 12 & -0.25 \\
\hline Chertow, 2010 [51] & $\geq 4 \times$ vs. $<4 x /$ week HD & 5 & 125 & 9 & 120 & 12 & -0.26 \\
\hline Rocco, 2011 [61] & $\geq 4 x$ vs. $<4 x /$ week $H D$ & 2 & 45 & 1 & 42 & 12 & -0.20 \\
\hline Chen, 2011 [57] & $\mathrm{HD}+$ hemoperfusion vs. $\mathrm{HD}$ & 6 & 51 & 14 & 49 & 24 & -5.50 \\
\hline Hur, 2013 [67] & Fluid management vs. standard HD & 2 & 78 & 4 & 78 & 12 & -0.39 \\
\hline Whalley, 2013 [68] & Early vs. later dialysis initiation & 2 & 91 & 1 & 91 & 12 & -0.20 \\
\hline Odudu, 2015 [74] & Individual dialysate cooling vs. standard & 2 & 36 & 1 & 37 & 12 & -0.34 \\
\hline Liu, 2016 [76] & Reduced dialysate sodium & 3 & 32 & 2 & 32 & 12 & -0.55 \\
\hline Marshall, 2020 [82] & Reduced dialysate sodium & 2 & 49 & 1 & 50 & 12 & -0.15 \\
\hline Jardine, 2017 [78] & Extended HD vs. standard & 5 & 100 & 2 & 100 & 12 & -0.19 \\
\hline Howden, 2013 [66] & Exercise vs. usual activity & 0 & 41 & 0 & 42 & 12 & -0.06 \\
\hline Schrier, 2002 [33] & Lower vs. higher blood pressure target & 1 & 42 & 1 & 37 & 84 & -0.92 \\
\hline Nakamura, 2002 [31] & Dilazep vs. placebo & 0 & 20 & 0 & 20 & 12 & -0.23 \\
\hline Hotu, 2010 [52] & Nurse/community vs. physician/clinic & 2 & 33 & 0 & 32 & 12 & -0.69 \\
\hline Zamboli, 2011 [62] & Furosemide vs. no furosemide & 0 & 20 & 0 & 20 & 12 & -0.55 \\
\hline Higuchi, 2016 [75] & Levocarnitine vs. no levocarnitine & 5 & 110 & 7 & 112 & 12 & -0.40 \\
\hline Lin, 2016 [77] & Spironolactone vs. placebo & 12 & 125 & 25 & 128 & 24 & -0.55 \\
\hline Miskulin, 2018 [79] & Lower vs. higher blood pressure target & 4 & 62 & 1 & 64 & 12 & -0.05 \\
\hline Fujii, 2018 [85] & Lanthanum carbonate vs. calcium carbonate & 1 & 50 & 1 & 55 & 18 & -0.07 \\
\hline Rutherford, 2021 [86] & Allopurinol vs. placebo & 2 & 40 & 5 & 40 & 12 & -0.10 \\
\hline Dorr, 2021 [84] & Etelcalcitide vs. alfacalcidol & 2 & 32 & 1 & 30 & 12 & -0.40 \\
\hline Edwards, 2021 [83] & Spironolactone vs. chlorthalidone & 0 & 77 & 0 & 77 & 40 & -0.12 \\
\hline Total or Median ${ }^{\mathrm{a}}$ & & 121 & 2584 & 168 & 2606 & 12 & -0.285 \\
\hline
\end{tabular}

$\triangle$ change, ESA erythropoietin-stimulating agent, F/U follow-up, HD hemodialysis, LVH left ventricular hypertrophy, LVM left ventricular mass, RAASi renin-angiotensinaldosterone system inhibitor, $S M D$ standardized mean difference

${ }^{a} \mathrm{~F} / \mathrm{U}$ and LVM $\triangle \mathrm{SMD}$ are medians, others are numbers 
Table 2 Relative risk of all-cause mortality in patients with chronic kidney disease in trials of $\geq 12$ months follow-up in which left ventricular mass was reduced in the intervention group relative to the control group and there was $\geq 1$ event in $\geq 1$ group

\begin{tabular}{|c|c|c|c|c|c|}
\hline \multirow[t]{2}{*}{ Author, Year } & \multirow[t]{2}{*}{$N$} & \multirow[t]{2}{*}{ RR } & \multicolumn{2}{|l|}{$95 \% \mathrm{Cl}$} & \multirow[t]{2}{*}{ \% Weight } \\
\hline & & & Lower & Upper & \\
\hline Schrier, 2002 [33] & 79 & 0.881 & 0.057 & 13.594 & 0.70 \\
\hline Levin, 2005 [37] & 172 & 0.341 & 0.036 & 3.216 & 1.05 \\
\hline Parfrey, 2005 [38] & 596 & 0.659 & 0.334 & 1.300 & 11.39 \\
\hline Yu, 2006 [40] & 46 & 2.760 & 0.118 & 64.415 & 0.53 \\
\hline Macdougall, 2007 [43] & 197 & 0.338 & 0.042 & 2.753 & 1.20 \\
\hline Cianciaruso, 2008 [45] & 95 & 3.191 & 0.133 & 76.419 & 0.52 \\
\hline Pappas, 2008 [46] & 31 & 0.356 & 0.041 & 3.055 & 1.14 \\
\hline Chertow, 2010 [51] & 245 & 0.533 & 0.184 & 1.546 & 4.65 \\
\hline Hotu, 2010 [52] & 65 & 4.853 & 0.242 & 97.313 & 0.59 \\
\hline Yilmaz, 2010 [54] & 112 & 0.333 & 0.014 & 8.011 & 0.52 \\
\hline Alvestrand, 2011 [56] & 48 & 0.519 & 0.095 & 2.827 & 1.83 \\
\hline Chen, 2011 [57] & 100 & 0.412 & 0.172 & 0.985 & 6.91 \\
\hline Rocco, 2011 [61] & 87 & 1.867 & 0.176 & 19.836 & 0.94 \\
\hline Hur, 2013 [67] & 156 & 0.500 & 0.094 & 2.651 & 1.89 \\
\hline Whalley, 2013 [68] & 182 & 2.000 & 0.185 & 21.671 & 0.93 \\
\hline Ito, 2014 [70] & 158 & 0.410 & 0.082 & 2.052 & 2.03 \\
\hline Mostovaya, 2014 [72] & 714 & 0.799 & 0.544 & 1.174 & 35.67 \\
\hline Odudu, 2015 [74] & 73 & 2.056 & 0.195 & 21.688 & 0.95 \\
\hline Higuchi, 2016 [75] & 222 & 0.727 & 0.238 & 2.222 & 4.22 \\
\hline Lin, 2016 [77] & 253 & 0.492 & 0.258 & 0.935 & 12.74 \\
\hline Liu, 2016 [76] & 64 & 1.500 & 0.268 & 8.383 & 1.78 \\
\hline Jardine, 2017 [78] & 200 & 2.500 & 0.497 & 12.585 & 2.01 \\
\hline Fujii, 2018 [85] & 105 & 1.100 & 0.071 & 17.125 & 0.70 \\
\hline Miskulin, 2018 [79] & 126 & 4.129 & 0.475 & 35.922 & 1.12 \\
\hline Marshall, 2020 [82] & 99 & 2.041 & 0.191 & 21.786 & 0.94 \\
\hline Rutherford, 2021 [86] & 80 & 0.400 & 0.082 & 1.942 & 2.11 \\
\hline Dorr, 2021 [84] & 62 & 1.875 & 0.179 & 19.625 & 0.95 \\
\hline Pooled $^{\mathrm{a}}$ & 4367 & 0.717 & 0.570 & 0.902 & 100.00 \\
\hline$Z=-2.84, P$ & $=0.0 \%$ & $\mathrm{Q}=1$ & $P_{\text {het }}$ & eity $=$ & \\
\hline
\end{tabular}

$\mathrm{Cl}$ confidence interval, $\mathrm{N}$ number, $R R$ relative risk

${ }^{a}$ Pooled estimates are from random effects analysis. Results from the fixed effect analyses were the same

categories of $\geq 6$ ( 34 trials), $\geq 9$ ( 29 trials), $\geq 12$ ( 27 trials) and $>12$ months (10 trials) were $-0.23,-0.25,-0.26$ and -0.28 standard deviations, respectively.

Subgroup analyses according to the type of intervention, LVM or LVMI change relative to -0.285 , which was the median standardized mean difference for LVM change from the analyses that included all studies, including those without events, according to enrollment of adults only or possible inclusion of children, and according to the presence or absence of ESKD are shown in Table 4. None of the subgroups according to type of intervention showed results that excluded the null with 95\% confidence, but all 3 of the main categories showed pooled RR values below 1.0 (ESA $R R=0.60$, RAASi $\mathrm{RR}=0.55$, and NCHD $\mathrm{RR}=0.78$ ). The 13 studies which had a change in LVM or LVMI $\leq-0.285$ had a RR $(95 \%$ CI) of 0.60 (0.41 to 0.88 ), whereas the 14 studies with a change $>-0.285$ had a RR ( $95 \% \mathrm{CI})$ of 0.80 (0.60 to 1.06 ) $(\mathrm{Q}=1.377$; $\mathrm{p}$ for heterogeneity between the point estimates for the subgroups $=0.241$ ). The 23 studies that enrolled only adult subjects had a RR $(95 \% \mathrm{CI})$ of 0.71 ( 0.56 to 0.91 ), whereas the 4 studies that enrolled children and adults $(n=2)$ or did not report the minimum subject age $(n=2)$ had a RR $(95 \%$ CI) of $0.77(0.34$ to 1.78) $(\mathrm{Q}=0.028$; $\mathrm{p}$ for heterogeneity between the point estimates for the subgroups $=0.866$ ). The 21 studies of subjects with ESKD had a RR (95\% CI) of 0.72 (0.57 to $0.91)$, whereas the 6 studies of subjects without ESKD had a RR (95\% CI) of 0.66 (0.24 to 1.81) $(\mathrm{Q}=0.028$; $\mathrm{p}$ for heterogeneity between the point estimates for the subgroups $=0.868$ ). Findings from analyses of the different minimum follow-up thresholds and subgroup analyses done by including all studies, including those without events, were similar to those which included only studies with at least 1 event in at least 1 group.

A total of 59 cardiovascular deaths were reported in 13 of the 42 qualifying trials: $23 / 2584(0.9 \%)$ subjects in the intervention groups and $36 / 2606$ (1.4\%) subjects in the control groups. The pooled RR $(95 \% \mathrm{CI})$ estimate from the analysis of cardiovascular mortality in patients with CKD in the 10 trials of at least 12 months follow-up in which LVM was reduced in the intervention group relative to the control group and there was at least 1 event in 1 group was 0.67 (0.39 to 1.16, $p=0.156)$. There was little heterogeneity across studies $\left(\mathrm{I}^{2}=0.0 \%, \mathrm{Q}=7.7\right.$, $\mathrm{p}$ for heterogeneity $\left.=0.562\right)$. The pooled $\mathrm{RR}$ for trials with $\geq 6$ months (13 trials) and $\geq 9$ months (11 trials) follow-up thresholds were identical to the $\geq 12$ months analysis, but the pooled RR for the three studies with $>12$ months of follow-up showed $58 \%$ lower cumulative cardiovascular mortality incidence $(p=0.013)$.

Mean change in standardized LVM was not a significant predictor of the effect size for all-cause mortality $(\beta=0.122,95 \% \mathrm{CI}=-0.048$ to $0.293, p=0.160$; $\left.\mathrm{R}^{2}=0.00\right)$ or cardiovascular mortality $(\beta=1.261,95 \%$ $\mathrm{CI}=-1.372$ to $3.894, p=0.348 ; \mathrm{R}^{2}=0.00$ ).

Risk of bias assessment for each of the 58 trials with $\geq 6$ months duration is included in Supplemental Table 3, and an assessment of the quality of evidence of these 58 trials using the GRADE approach is included in Supplemental Table 4. The mean quality of evidence for ESA treating to higher vs. lower hemoglobin targets was of moderate quality, whereas the studies for RAASi, hemodialysis and other interventions were considered to be of low- to moderate quality. 


\begin{tabular}{|c|c|c|c|c|c|}
\hline \multirow[t]{2}{*}{ Author, Year } & \multicolumn{4}{|c|}{ Statistics for each study } & \multirow[b]{2}{*}{$\begin{array}{r}\text { Relative } \\
\text { weight }\end{array}$} \\
\hline & $\begin{array}{l}\text { Risk } \\
\text { ratio }\end{array}$ & $\begin{array}{c}\text { Lower } \\
\text { limit }\end{array}$ & $\begin{array}{c}\text { Upper } \\
\text { limit }\end{array}$ & p-Value & \\
\hline Schrier, 2002 & 0.881 & 0.057 & 13.594 & 0.928 & 0.70 \\
\hline Levin, 2005 & 0.341 & 0.036 & 3.216 & 0.347 & 1.05 \\
\hline Parfrey, 2005 & 0.659 & 0.334 & 1.300 & 0.229 & 11.39 \\
\hline Yu, 2006 & 2.760 & 0.118 & 64.415 & 0.528 & 0.53 \\
\hline Macdougall, 2007 & 0.338 & 0.042 & 2.753 & 0.311 & 1.20 \\
\hline Cianciaruso, 2008 & 3.191 & 0.133 & 76.419 & 0.474 & 0.52 \\
\hline Pappas, 2008 & 0.356 & 0.041 & 3.055 & 0.346 & 1.14 \\
\hline Chertow, 2010 & 0.533 & 0.184 & 1.546 & 0.247 & 4.65 \\
\hline Hotu, 2010 & 4.853 & 0.242 & 97.313 & 0.302 & 0.59 \\
\hline Yilmaz, 2010 & 0.333 & 0.014 & 8.011 & 0.498 & 0.52 \\
\hline Alvestrand, 2011 & 0.519 & 0.095 & 2.827 & 0.448 & 1.83 \\
\hline Chen, 2011 & 0.412 & 0.172 & 0.985 & 0.046 & 6.91 \\
\hline Rocco, 2011 & 1.867 & 0.176 & 19.836 & 0.605 & 0.94 \\
\hline Hur, 2013 & 0.500 & 0.094 & 2.651 & 0.415 & 1.89 \\
\hline Whalley, 2013 & 2.000 & 0.185 & 21.671 & 0.569 & 0.93 \\
\hline Ito, 2014 & 0.410 & 0.082 & 2.052 & 0.278 & 2.03 \\
\hline Mostovaya, 2014 & 0.799 & 0.544 & 1.174 & 0.253 & 35.67 \\
\hline Odudu, 2015 & 2.056 & 0.195 & 21.688 & 0.549 & 0.95 \\
\hline Higuchi, 2016 & 0.727 & 0.238 & 2.222 & 0.576 & 4.22 \\
\hline Lin, 2016 & 0.492 & 0.258 & 0.935 & 0.030 & 12.74 \\
\hline Liu, 2016 & 1.500 & 0.268 & 8.383 & 0.644 & 1.78 \\
\hline Jardine, 2017 & 2.500 & 0.497 & 12.585 & 0.266 & 2.01 \\
\hline Fujii, 2018 & 1.100 & 0.071 & 17.125 & 0.946 & 0.70 \\
\hline Miskulin, 2018 & 4.129 & 0.475 & 35.922 & 0.199 & 1.12 \\
\hline Marshall, 2020 & 2.041 & 0.191 & 21.786 & 0.555 & 0.94 \\
\hline Dorr, 2021 & 1.875 & 0.179 & 19.625 & 0.600 & 0.95 \\
\hline Rutherford, 2021 & 0.400 & 0.082 & 1.942 & 0.256 & 2.11 \\
\hline
\end{tabular}

\section{Discussion}

The results of this meta-analysis demonstrated a pooled RR estimate of 0.72 ( 0.57 to $0.90, p=0.005)$, indicating $28 \%$ lower mortality in groups with treatment-induced reductions in LVM relative to control over periods of $\geq 12$ months. It is further notable that the pooled RR for studies with $>12$ months (median 24 months) follow-up showed $47 \%$ lower cumulative mortality (RR 0.53, 95\% CI 0.37 to 0.77 ). No significant heterogeneity was observed overall. None of the 3 main subgroups of intervention

Table 3 Sensitivity analyses for the pooled relative risk of all-cause mortality in patients with chronic kidney disease using different minimum follow-up thresholds for studies in which left ventricular mass was reduced in the intervention group relative to the control group and there was $\geq 1$ event in $\geq 1$ group ${ }^{a}$

\begin{tabular}{llllll}
\hline Follow-up & Number of Trials & Intervention, Events/n & Control, Events/n & Pooled RR & 95\% Cl \\
\hline$\geq 6$ Months & 34 & $135 / 2541$ & $177 / 2560$ & 0.74 & 0.59 to 0.92 \\
$\geq 9$ Months & 29 & $121 / 2210$ & $171 / 2302$ & 0.71 & 0.57 to 0.90 \\
$\geq 12$ Months & $\mathbf{2 7}$ & $\mathbf{1 2 1 / 2 1 5 1}$ & $\mathbf{1 6 8 / 2 2 1 6}$ & $\mathbf{0 . 7 2}$ & $\mathbf{0 . 5 7}$ to 0.90 \\
$>12$ Months & 10 & $40 / 865$ & $78 / 938$ & 0.53 & 0.37 to 0.77 \\
\hline
\end{tabular}

$C l$ confidence interval, $R R$ relative risk

a Pooled estimates are from random effects analysis. The category of $\geq 12$ months of follow-up is shown in bold because it was the prespecified primary minimum follow-up threshold. Median reductions in LVM in the intervention groups compared with the control groups were $-0.23,-0.25,-0.26$ and -0.28 standardized mean differences in the categories of, $\geq 6, \geq 9, \geq 12$ and $>12$ months, respectively

${ }^{\mathrm{b}} \mathrm{P}_{\text {-heterogeneity }}=0.923$ for $\geq 6$ months, 0.898 for $\geq 9$ months, 0.851 for $\geq 12$ months, and 0.971 for $>12$ months 
Table 4 Subgroup analyses by type of intervention, according to LVM or LVMI change relative to the median, according to whether the study possibly included children, and according to the presence or absence of ESKD for the pooled relative risk of all-cause mortality in patients with chronic kidney disease in studies with $\geq 12$ months of follow-up in which left ventricular mass was reduced in the intervention group relative to the control group and there was $\geq 1$ event in $\geq 1$ group

\begin{tabular}{|c|c|c|c|c|c|}
\hline $\begin{array}{l}\text { Intervention/ degree of LVM(I) } \\
\Delta / \text { ESKD status/or Age, number } \\
\text { of studies }\end{array}$ & $\begin{array}{l}\text { Intervention } \\
\text { Events/subjects }\end{array}$ & $\begin{array}{l}\text { Control } \\
\text { Events/subjects }\end{array}$ & Median F/U, LVM $\Delta^{\mathrm{a}}$ & Pooled RR & $95 \% \mathrm{Cl}$ \\
\hline $\mathrm{ESA}, 5$ & $17 / 507$ & $32 / 584$ & $24,-0.20$ & 0.60 & 0.34 to 1.08 \\
\hline RAASi, 3 & $3 / 158$ & $6 / 158$ & $12,-0.34$ & 0.55 & 0.15 to 2.03 \\
\hline $\mathrm{NCHD}^{c}, 11$ & $72 / 992$ & $89 / 976$ & $12,-0.26$ & 0.78 & 0.58 to 1.06 \\
\hline Other, 8 & $29 / 494$ & $41 / 498$ & $12,-0.40$ & 0.67 & 0.42 to 1.08 \\
\hline$>-0.285^{d}, 14$ & $80 / 1468$ & $102 / 1542$ & $12,-0.17$ & 0.80 & 0.60 to 1.06 \\
\hline$\leq-0.285,13$ & $41 / 683$ & $66 / 674$ & $12,-0.51$ & 0.60 & 0.41 to 0.88 \\
\hline Adults only, 23 & 111/1902 & 155/1971 & $12,-0.25$ & 0.71 & 0.56 to 0.91 \\
\hline Included children/unclear, 4 & $10 / 249$ & $13 / 245$ & $12,-0.30$ & 0.77 & 0.34 to 1.78 \\
\hline ESKD, 21 & $114 / 1865$ & $155 / 1863$ & $12,-0.26$ & 0.72 & 0.57 to 0.92 \\
\hline Non-ESKD, 6 & $7 / 286$ & $13 / 353$ & $24,-0.47$ & 0.66 & 0.24 to 1.81 \\
\hline
\end{tabular}

$\Delta$ change, $C l$ confidence interval, ESA erythropoietin stimulating agent/higher vs. lower hemoglobin target, ESKD end stage kidney disease, F/U follow-up, LVM left ventricular mass, NCHD non-conventional vs. conventional hemodialysis, RAASi renin-angiotensin-aldosterone system inhibitor vs. placebo or standard treatment, $R R$ relative risk

${ }^{\text {a }}$ Units for F/U are months and for LVM $\Delta$ are standardized mean differences; results are for random effects analysis

${ }^{\mathrm{b}} \mathrm{P}_{\text {-heterogeneity }}=0.828$ for intervention, 0.241 for $\operatorname{LVM}(\mathrm{I}) \Delta, 0.868$ for ESKD status, and 0.866 for age

' NCHD includes convective hemodialysis, more frequent hemodialysis ( $\geq 4 x$ per week), earlier start to hemodialysis, hemodialysis with hemoperfusion, fluid management during hemodialysis, and reduced dialysate sodium

${ }^{d}$ The cutpoint of -0.285 is the standardized mean difference from the sensitivity analysis, which included all studies with $\geq 12$ months of follow-up, including those with no events

type showed statistically significant results individually, but the directionality of the association was the same for each intervention type, and no statistically significant heterogeneity was noted across intervention types. Studies of subjects with ESKD showed a statistically significant reduction in mortality with treatment-induced reduction in LVM, whereas studies in subjects without ESKD did not show a significant effect, although results were similar and there was no statistically significant heterogeneity. The lack of significance in the non-ESKD subgroup was likely due to the smaller number of studies and deaths that occurred in these studies. Higher LVM has been shown to predict increased mortality risk in several patient populations, including patients with hypertension without CKD. Thus, the authors do not view it as likely that changes in LVM are less clinically important in patients with pre-ESKD.

Authors of a previous meta-regression analysis concluded that there was no compelling relationship between changes in LVM and mortality [21]. However, many of the studies included in that analysis were limited by short duration of follow-up and minimal differences between treatment arms for changes in LVM, with some of the interventions producing an increase in LVM. The present meta-analysis avoided those limitations by examining only studies that showed some degree of relative LVM reduction in studies of $\geq 12$ months duration. However, the various interventions investigated in the included studies did not always produce reductions in LVM. Furthermore, in clinical practice, several interventions are often used simultaneously, which will result in a combined effect on LVM. The results from this meta-analysis suggest that a reduction in LVM should be considered a favorable clinical result, although prospective trials are needed to assess the use of LVM as a surrogate marker. A post-hoc meta-regression analysis indicated that degree of change in standardized LVM was not a significant predictor of the effect size for all-cause or cardiovascular mortality. However, the power of this analysis is diminished due to the restricted range of observed changes in LVM. Thus, the authors do not believe that this finding detracts from the main finding that regression of LVM was associated with reduced mortality.

The results from the LIFE study demonstrated that reversion from LVH to normal LVMI induced by antihypertensive therapy did not produce material reductions in adverse outcomes for several months [10]. Each SD reduction in LVMI was associated with a reduction of $26 \%$ (95\% CI 7 to $41 \%, p=0.008$ ) in all-cause mortality and a reduction of $34 \%$ (95\% CI 10 to $51 \%, p=0.009$ ) in cardiovascular mortality over the full study period in models adjusted for several covariates. Based on results 
from the LIFE study, the median reduction of $0.285 \mathrm{SD}$ in the present meta-analysis would have been predicted to produce a $\sim 8 \%$ reduction in all-cause mortality. The larger mortality reductions observed of $28 \%$ in studies with $\geq 12$ months of follow-up, and $47 \%$ in studies with $>12$ months of follow-up, might be attributable to markedly higher average mortality risk in the studies included in the analysis: $6.5 \%$ cumulative mortality in the control conditions over a median follow-up period of 1 year, compared to approximately $1.4 \%$ per year over a median follow-up period of 4.8 years in LIFE [10].

In patients with CKD, total mortality is increased due to several types of events, but CVD mortality accounts for a large proportion of deaths, exceeding $50 \%$ in those with end-stage disease [17-20]. In prior studies, such as LIFE, there was a strong concordance between the effects of treatment-induced changes in LVM and results for total and cardiovascular mortality [6, 10, 87]. In the present investigation, the result for cardiovascular mortality was not statistically significant in the main analysis that included studies of at least 12 months of follow-up, but the pattern and point estimates were similar to those for the analysis of all-cause mortality, suggesting that the lack of statistical significance may have been due to insufficient statistical power.

CKD and CVD share several risk factors, such as hypertension, vascular stiffness, and endothelial dysfunction [88]. LVH is highly prevalent in CKD patients and is associated with risk of mortality and unfavorable prognosis $[7,89,90]$. In addition, CKD patients show progressively increasing LVM with decreased renal function [90]. Increased CVD mortality in CKD results from higher incidence of atherosclerotic and non-atherosclerotic (particularly arrhythmic) cardiovascular events $[19,20$, 91-93]. LVM regression has been associated with reductions in both types of events [92].

LVM regression is typically associated with decreased myocardial fibrosis, which is clinically relevant because the degree of fibrosis is a strong predictor of ventricular arrhythmia risk [20]. The pathophysiologic mechanisms leading to $\mathrm{LVH}$ in CKD patients include additive and synergistic effects of afterload and preload factors [19]. Afterload factors, such as increased systemic arterial resistance and arterial blood pressure, and reduced large vessel compliance, lead to myocardial cell thickening and left ventricular remodeling, along with activation of the intracardiac renin-angiotensin system, which promotes cardiac fibrosis. Preload factors, including intravascular volume expansion, secondary anemia, and arteriovenous fistulas, also result in myocardial cell lengthening and left ventricular remodeling [94]. The hypertrophy of the myocardium activates cellular apoptosis and increases extracellular matrix production resulting in fibrosis [94].
Fibrosis impairs the contractility of the myocardium and causes systolic and diastolic dysfunction, potentially leading to congestive heart failure and disturbances in cardiac electrophysiology.

The present analysis was limited by the fact that patient-level data were not available, therefore only summary data could be included and the number of subjects in each type of intervention was relatively small. Because a relatively small number of studies reported cardiovascular mortality, the analysis had low statistical power for detection of an effect for this outcome. Nevertheless, the results are supportive of the conclusion that LVM regression produced by several types of interventions in patients with CKD is predictive of lower risk for all-cause mortality, which may be attributable, at least in part, to reduced cardiovascular mortality. The finding of lower all-cause mortality with LVM regression was robust in several subgroup and sensitivity analyses.

\section{Conclusions}

Current strategies to reduce cardiovascular risk in CKD focus on control of blood pressure, fluid volume, lipids (in earlier stages), glycemic control for those with diabetes, and correction of anemia. The results from this meta-analysis show that interventions that lower LVM are associated with a significant reduction in pooled risk for all-cause mortality in CKD patients. Thus, monitoring LVM in patients with CKD may be helpful to identify those at increased risk for mortality; further, LVM change may be useful as a surrogate marker for benefits of interventions intended to reduce mortality risk in CKD.

\section{Abbreviations \\ $\triangle$ : Change; CKD: Chronic kidney disease; Cl: Confidence interval; ESA: Eryth- ropoietin stimulating agent; ESKD: End stage kidney disease; F/U: Follow-up; GRADE: Grading of Recommendations Assessment, Development and Evalu- ation; HD: Hemodialysis; LIFE: Losartan Intervention for Endpoint Reduction in Hypertension; LVH: Left ventricular hypertrophy; LVM: Left ventricular mass; LVMI: Left ventricular mass index; N: Number; NCHD: Non-conventional hemo- dialysis; $R_{*}^{2}$ : Percentage of between-study heterogeneity explained by the predictor in a meta-regression; RAASi: Renin-angiotensin-aldosterone system inhibitor; RCT: Randomized controlled trial; RR: Relative risk; SD: Standard deviation; SMD: Standardized mean difference.}

\section{Supplementary Information}

The online version contains supplementary material available at https://doi. org/10.1186/s12882-022-02666-1.

Additional file 1: Table S1. Search terms utilized for the PubMed database literature search (originally utilized by Badve et al. 2016). Figure S1. PRISMA flow diagram. Table S2. Individual study details. Table S3. Risk of bias assessment including studies with $\geq 6$ months of follow-up that observed a reduction in LVM/LVMI. Table S4. Assessment of the quality of evidence using the GRADE approach. 


\section{Acknowledgements}

We gratefully acknowledge Lisa Sanders of Midwest Biomedical Research and Heather Nelson Cortes of Kyzo Nutrition, LLC for their assistance with data extraction and manuscript preparation.

\section{Authors' contributions}

K.C.M., R.K., and M.H.D. were responsible for the conception of the idea for the meta-analysis. All authors were involved in the design of the study. K.C.M., M.L.W., and M.R.D. were responsible for the extraction and analysis of the data. All authors were involved in the interpretation of the results and drafting and editing the manuscript, and all authors approved the final manuscript.

\section{Funding}

This meta-analysis was funded by Corvidia Therapeutics, Inc., Waltham, MA, USA, which has since been acquired by Novo Nordisk A/S.

\section{Availability of data and materials}

Not applicable.

\section{Declarations}

\section{Ethics approval and consent to participate} Not applicable.

\section{Consent for publication}

Not applicable.

\section{Competing interests}

M.H.D. and R.K. are former employees of Corvidia Therapeutics, Inc. As employees of Midwest Biomedical Research, K.C.M., M.L.W., and M.R.D. received research support from Corvidia Therapeutics, Inc.

\section{Author details}

${ }^{1}$ Department of Applied Health Science, Indiana University School of Public Health, 1025 E 7th St \#111, Bloomington, IN 47405, USA. ${ }^{2}$ Midwest Biomedical Research, Addison, IL, USA. ${ }^{3}$ Brigham and Women's Hospital, Boston, MA, USA. ${ }^{4}$ University of Chicago Pritzker School of Medicine, Chicago, IL, USA.

\section{Received: 8 July 2021 Accepted: 3 January 2022}

Published online: 16 January 2022

\section{References}

1. LV JC, Zhang LX. Prevalence and disease burden of chronic kidney disease. Adv Exp Med Biol. 2019;1165:3-15.

2. United States Renal Data System. 2017 annual data report. Volume 1: Chronic kidney disease in the United States. 2017. https://www.usrds.org/ annual-data-report/previous-adrs/. Accessed 2020.

3. United States Renal Data System. 2017 annual data report. Volume 2: End-stage renal disease in the United States. 2017. https://www.usrds. org/annual-data-report/previous-adrs/. Accessed 2020.

4. Levy D, Garrison RJ, Savage DD, Kannel WB, Castelli WP. Prognostic implications of echocardiographically determined left ventricular mass in the Framingham Heart Study. N Engl J Med. 1990;322(22):1561-6.

5. Foley RN, Parfrey PS, Harnett JD, Kent GM, Martin CJ, Murray DC, et al. Clinical and echocardiographic disease in patients starting end-stage renal disease therapy. Kidney Int. 1995;47(1):186-92.

6. London GM, Pannier B, Guerin AP, Blacher J, Marchais SJ, Darne B, et al. Alterations of left ventricular hypertrophy in and survival of patients receiving hemodialysis: follow-up of an interventional study. J Am Soc Nephrol. 2001;12(12):2759-67.

7. Paoletti E, Bellino D, Cassottana P, Rolla D, Cannella G. Left ventricular hypertrophy in nondiabetic predialysis CKD. Am J Kidney Dis. 2005;46(2):320-7

8. Campese VM. Left ventricular function and chronic kidney disease: How soon does it start? Nephrol Dial Transplant. 2014;29(11):1989-91.

9. Verdecchia P, Angeli F, Borgioni C, Gattobigio R, de Simone G, Devereux $\mathrm{RB}$, et al. Changes in cardiovascular risk by reduction of left ventricular mass in hypertension: A meta-analysis. Am J Hypertens. 2003;16(11 Pt 1):895-9.

10. Devereux RB, Dahlöf B, Gerdts E, Boman K, Nieminen MS, Papademetriou $V$, et al. Regression of hypertensive left ventricular hypertrophy by losartan compared with atenolol: The losartan intervention for endpoint reduction in hypertension (LIFE) trial. Circulation. 2004:110(11):1456-62.

11. Devereux RB, Wachtell K, Gerdts E, Boman K, Nieminen MS, Papademetriou $V$, et al. Prognostic significance of left ventricular mass change during treatment of hypertension. JAMA. 2004;292(19):2350-6.

12. Verma A, Meris A, Skali H, Ghali JK, Arnold JM, Bourgoun M, et al. Prognostic implications of left ventricular mass and geometry following myocardial infarction: The VALIANT (valsartan in acute myocardial infarction) echocardiographic study. JACC Cardiovasc Imaging. 2008;1(5):582-91.

13. Pierdomenico SD, Cuccurullo F. Risk reduction after regression of echocardiographic left ventricular hypertrophy in hypertension: A meta-analysis. Am J Hypertens. 2010;23(8):876-81.

14. Liu S, Zhang DL, Guo W, Cui WY, Liu WH. Left ventricular mass index and aortic arch calcification score are independent mortality predictors of maintenance hemodialysis patients. Hemodial Int. 2012;16(4):504-11.

15. Stevens SM, Reinier K, Chugh SS. Increased left ventricular mass as a predictor of sudden cardiac death: Is it time to put it to the test? Circ Arrhythm Electrophysiol. 2013;6(1):212-7.

16. Park JS, Shin JS, Lee YH, Seo KW, Choi BJ, Choi SY, et al. Prognostic impact of left ventricular mass change in patients with ST-elevation myocardial infarction. Medicine (Baltimore). 2018;97(4):e9748.

17. Glassock RJ, Pecoits-Filho R, Barberato SH. Left ventricular mass in chronic kidney disease and ESRD. Clin J Am Soc Nephrol. 2009;4(Suppl 1):S79-91.

18. Charytan D. Is left ventricular hypertrophy a modifiable risk factor in endstage renal disease. Curr Opin Nephrol Hypertens. 2014:23(6):578-85.

19. Di Lullo L, Gorini A, Russo D, Santoboni A, Ronco C. Left ventricular hypertrophy in chronic kidney disease patients: From pathophysiology to treatment. Cardiorenal Med. 2015;5(4):254-66.

20. Rutherford E, Mark PB. What happens to the heart in chronic kidney disease? J R Coll Phys Edinb. 2017;47(1):76-82.

21. Badve SV, Palmer SC, Strippoli GFM, Roberts MA, Teixeira-Pinto A, Boudville $\mathrm{N}$, et al. The validity of left ventricular mass as a surrogate end point for all-cause and cardiovascular mortality outcomes in people with CKD: A systematic review and meta-analysis. Am J Kidney Dis. 2016;68(4):554-63.

22. Moher D, Liberati A, Tetzlaff J, Altman DG. Preferred reporting items for systematic reviews and meta-analyses: The PRISMA statement. J Clin Epidemiol. 2009;62(10):1006-12.

23. Rao G, Lopez-Jimenez F, Boyd J, D'Amico F, Durant NH, Hlatky MA, et al. Methodological standards for meta-analyses and qualitative systematic reviews of cardiac prevention and treatment studies: A scientific statement from the American Heart Association. Circulation. 2017;136(10):e172-e94.

24. Higgins JPT, Green S. Chapter 9: Analyzing data and undertaking metaanalyses. In: Cochrane handbook for systematic review of interventions; 2011.

25. Borenstein M, Hedges LV, Higgins JP, Rothstein HR. A basic introduction to fixed-effect and random-effects models for meta-analysis. Res Synth Methods. 2010;1(2):97-111.

26. Egger M, Davey Smith G, Schneider M, Minder C. Bias in meta-analysis detected by a simple, graphical test. BMJ. 1997;315(7109):629-34.

27. Sterne JA, Egger M. Funnel plots for detecting bias in meta-analysis: Guidelines on choice of axis. J Clin Epidemiol. 2001;54(10):1046-55.

28. Guyatt GH, Oxman AD, Vist GE, Kunz R, Falck-Ytter Y, Alonso-Coello P, et al. GRADE: An emerging consensus on rating quality of evidence and strength of recommendations. BMJ. 2008;336(7650):924-6.

29. London GM, Pannier B, Guerin AP, Marchais SJ, Safar ME, Cuche JL. Cardiac hypertrophy, aortic compliance, peripheral resistance, and wave reflection in end-stage renal disease. Comparative effects of ACE inhibition and calcium channel blockade. Circulation. 1994;90(6):2786-96.

30. Schrander-vd Meer AM, ter Wee PM, Kan G, Donker AJ, van Dorp WT. Improved cardiovascular variables during acetate free biofiltration. Clin Nephrol. 1999;51(5):304-9. 
31. Nakamura T, Ushiyama C, Osada S, Ugai K, Takahashi Y, Tanaka A, et al. Effect of dilazep dihydrochloride on serum cardiac troponin t levels in hemodialysis patients. Kidney Blood Press Res. 2002;25(1):50-4

32. Shibasaki Y, Masaki H, Nishiue T, Nishikawa M, Matsubara H, Iwasaka T. Angiotensin ii type 1 receptor antagonist, losartan, causes regression of left ventricular hypertrophy in end-stage renal disease. Nephron. 2002;90(3):256-61.

33. Schrier R, McFann K, Johnson A, Chapman A, Edelstein C, Brosnahan $G$, et al. Cardiac and renal effects of standard versus rigorous blood pressure control in autosomal-dominant polycystic kidney disease: Results of a seven-year prospective randomized study. J Am Soc Nephrol. 2002;13(7):1733-9.

34. Suzuki H, Kanno Y, Ikeda N, Nakamoto H, Okada H, Sugahara S. Selection of the dose of angiotensin converting enzyme inhibitor for patients with diabetic nephropathy depends on the presence or absence of left ventricular hypertrophy. Hypertens Res. 2002;25(6):865-73.

35. Suzuki $H$, Nakamoto $H$, Okada H, Sugahara S, Kanno Y. A selective angiotensin receptor antagonist, valsartan, produced regression of left ventricular hypertrophy associated with a reduction of arterial stiffness. Adv Perit Dial. 2003:19:59-66.

36. Kanno Y, Kaneko K, Kaneko M, Kotaki S, Mimura T, Takane H, et al. Angiotensin receptor antagonist regresses left ventricular hypertrophy associated with diabetic nephropathy in dialysis patients. J Cardiovasc Pharmacol. 2004;43(3):380-6.

37. Levin A, Djurdjev O, Thompson C, Barrett B, Ethier J, Carlisle E, et al. Canadian randomized trial of hemoglobin maintenance to prevent or delay left ventricular mass growth in patients with CKD. Am J Kidney Dis. 2005;46(5):799-811.

38. Parfrey PS, Foley RN, Wittreich BH, Sullivan DJ, Zagari MJ, Frei D. Doubleblind comparison of full and partial anemia correction in incident hemodialysis patients without symptomatic heart disease. J Am Soc Nephrol. 2005;16(7):2180-9.

39. Matsumoto N, Ishimitsu T, Okamura A, Seta H, Takahashi M, Matsuoka $H$. Effects of imidapril on left ventricular mass in chronic hemodialysis patients. Hypertens Res. 2006:29(4):253-60.

40. Yu WC, Lin YP, Lin IF, Chuang SY, Chen CH. Effect of ramipril on left ventricular mass in normotensive hemodialysis patients. Am J Kidney Dis. 2006;47(3):478-84.

41. Culleton BF, Walsh M, Klarenbach SW, Mortis G, Scott-Douglas N, Quinn $R R$, et al. Effect of frequent nocturnal hemodialysis vs conventional hemodialysis on left ventricular mass and quality of life: A randomized controlled trial. JAMA. 2007:298(11):1291-9.

42. Feldt-Rasmussen B, Lange M, Sulowicz W, Gafter U, Lai KN, Wiedemann J, et al. Growth hormone treatment during hemodialysis in a randomized trial improves nutrition, quality of life, and cardiovascular risk. J Am Soc Nephrol. 2007:18(7):2161-71.

43. Macdougall IC, Temple RM, Kwan JT. Is early treatment of anaemia with epoetin-alpha beneficial to pre-dialysis chronic kidney disease patients? Results of a multicentre, open-label, prospective, randomized, comparative group trial. Nephrol Dial Transplant. 2007;22(3):784-93.

44. Ritz E, Laville M, Bilous RW, O'Donoghue D, Scherhag A, Burger U, et al. Target level for hemoglobin correction in patients with diabetes and CKD: Primary results of the anemia correction in diabetes (ACORD) study. Am J Kidney Dis. 2007;49(2):194-207.

45. Cianciaruso B, Ravani P, Barrett BJ, Levin A. Italian randomized trial of hemoglobin maintenance to prevent or delay left ventricular hypertrophy in chronic kidney disease. J Nephrol. 2008;21(6):861-70.

46. Pappas KD, Gouva CD, Katopodis KP, Nikolopoulos PM, KorantzopouIos PG, Michalis LK, et al. Correction of anemia with erythropoietin in chronic kidney disease (stage 3 or 4): Effects on cardiac performance. Cardiovasc Drugs Ther. 2008;22(1):37-44.

47. Zeltner R, Poliak R, Stiasny B, Schmieder RE, Schulze BD. Renal and cardiac effects of antihypertensive treatment with ramipril vs metoprolol in autosomal dominant polycystic kidney disease. Nephrol Dial Transplant. 2008;23(2):573-9.

48. Katopodis KP, Dounousi E, Challa A, Pappas K, Kalaitzidis R, SiamopouIos KC. Switch from conventional to every other day hemodialysis: A comparison pilot study. ASAIO J. 2009;55(1):41-6.

49. Mitsuhashi H, Tamura K, Yamauchi J, Ozawa M, Yanagi M, Dejima T, et al. Effect of losartan on ambulatory short-term blood pressure variability and cardiovascular remodeling in hypertensive patients on hemodialysis. Atherosclerosis. 2009;207(1):186-90.

50. Taheri S, Mortazavi M, Shahidi S, Pourmoghadas A, Garakyaraghi M, Seirafian S, et al. Spironolactone in chronic hemodialysis patients improves cardiac function. Saudi J Kidney Dis Transpl. 2009;20(3):392-7.

51. Chertow GM, Levin NW, Beck GJ, Depner TA, Eggers PW, Gassman JJ, et al. In-center hemodialysis six times per week versus three times per week. N Engl J Med. 2010;363(24):2287-300.

52. Hotu C, Bagg W, Collins J, Harwood L, Whalley G, Doughty R, et al. A community-based model of care improves blood pressure control and delays progression of proteinuria, left ventricular hypertrophy and diastolic dysfunction in Maori and Pacific patients with type 2 diabetes and chronic kidney disease: A randomized controlled trial. Nephrol Dial Transplant. 2010;25(10):3260-6.

53. Ulusoy S, Ozkan G, Orem C, Kaynar K, Koşucu P, Kiriş A. A comparison of the effects of ramipril and losartan on blood pressure control and left ventricle hypertrophy in patients with autosomal dominant polycystic kidney disease. Ren Fail. 2010;32(8):913-7.

54. Yilmaz R, Altun B, Kahraman S, Ozer N, Akinci D, Turgan C. Impact of amlodipine or ramipril treatment on left ventricular mass and carotid intima-media thickness in nondiabetic hemodialysis patients. Ren Fail. 2010;32(8):903-12.

55. Akizawa T, Gejyo F, Nishi S, lino Y, Watanabe Y, Suzuki M, et al. Positive outcomes of high hemoglobin target in patients with chronic kidney disease not on dialysis: A randomized controlled study. Ther Apher Dial. 2011;15(5):431-40.

56. Alvestrand A, Ledebo I, Hagerman I, Wingren K, Mattsson E, Qureshi $A R$, et al. Left ventricular hypertrophy in incident dialysis patients randomized to treatment with hemofiltration or hemodialysis: Results from the PROFIL study. Blood Purif. 2011;32(1):21-9.

57. Chen SJ, Jiang GR, Shan JP, Lu W, Huang HD, Ji G, et al. Combination of maintenance hemodialysis with hemoperfusion: A safe and effective model of artificial kidney. Int J Artif Organs. 2011;34(4):339-47.

58. Kao MP, Ang DS, Gandy SJ, Nadir MA, Houston JG, Lang CC, et al. Allopurinol benefits left ventricular mass and endothelial dysfunction in chronic kidney disease. J Am Soc Nephrol. 2011;22(7):1382-9.

59. Li H, Wang SX. Improvement of hypertension and LVH in maintenance hemodialysis patients treated with sustained-release isosorbide mononitrate. J Nephrol. 2011;24(2):236-45.

60. Li H, Wang S. Organic nitrates favor regression of left ventricular hypertrophy in hypertensive patients on chronic peritoneal dialysis. Int J Mol Sci. 2013;14(1):1069-79.

61. Rocco MV, Lockridge RS Jr, Beck GJ, Eggers PW, Gassman JJ, Greene $T$, et al. The effects of frequent nocturnal home hemodialysis: The frequent hemodialysis network nocturnal trial. Kidney Int. 2011:80(10):1080-91.

62. Zamboli P, De Nicola L, Minutolo R, Chiodini P, Crivaro M, Tassinario $S$, et al. Effect of furosemide on left ventricular mass in non-dialysis chronic kidney disease patients: A randomized controlled trial. Nephrol Dial Transplant. 2011;26(5):1575-83.

63. Ivarsen P, Povlsen JV, Christensen KL. Effect of alfacalcidol on cardiac function in patients with chronic kidney disease stage 4 and secondary hyperparathyroidism: A pilot study. Scand J Urol Nephrol. 2012;46(5):381-8

64. Ohtake T, Oka M, Ishioka K, Honda K, Mochida Y, Maesato K, et al. Cardiovascular protective effects of on-line hemodiafiltration: Comparison with conventional hemodialysis. Ther Apher Dial. 2012;16(2):181-8.

65. Maduell F, Arias M, Durán CE, Vera M, Fontseré N, Azqueta M, et al. Nocturnal, every-other-day, online haemodiafiltration: An effective therapeutic alternative. Nephrol Dial Transplant. 2012;27(4):1619-31.

66. Howden EJ, Leano R, Petchey W, Coombes JS, Isbel NM, MarwickTH. Effects of exercise and lifestyle intervention on cardiovascular function in CKD. Clin J Am Soc Nephrol. 2013;8(9):1494-501.

67. Hur E, Usta M, Toz H, Asci G, Wabel P, Kahvecioglu S, et al. Effect of fluid management guided by bioimpedance spectroscopy on cardiovascular parameters in hemodialysis patients: A randomized controlled trial. Am J Kidney Dis. 2013;61(6):957-65.

68. Whalley GA, Marwick TH, Doughty RN, Cooper BA, Johnson DW, Pilmore A, et al. Effect of early initiation of dialysis on cardiac structure and function: Results from the ECHO substudy of the IDEAL trial. Am J Kidney Dis. 2013:61(2):262-70. 
69. Dreyer G, Tucker AT, Harwood SM, Pearse RM, Raftery MJ, Yaqoob MM. Ergocalciferol and microcirculatory function in chronic kidney disease and concomitant vitamin D deficiency: An exploratory, double blind, randomised controlled trial. PLoS One. 2014;9(7):e99461.

70. Ito Y, Mizuno M, Suzuki Y, Tamai H, Hiramatsu T, Ohashi H, et al. Long-term effects of spironolactone in peritoneal dialysis patients. J Am Soc Nephrol. 2014;25(5):1094-102.

71. Liu S, Diao Z, Zhang D, Ding J, Cui W, Liu W. Preservation of residual renal function by not removing water in new hemodialysis patients: A randomized, controlled study. Int Urol Nephrol. 2014;46(1):83-90.

72. Mostovaya IM, Bots ML, van den Dorpel MA, Grooteman MP, Kamp O, Levesque $\mathrm{R}$, et al. A randomized trial of hemodiafiltration and change in cardiovascular parameters. Clin J Am Soc Nephrol. 2014;9(3):520-6.

73. Feniman-De-Stefano GM, Zanati-Basan SG, De Stefano LM, Xavier PS, Castro AD, Caramori JC, et al. Spironolactone is secure and reduces left ventricular hypertrophy in hemodialysis patients. Ther Adv Cardiovasc Dis. 2015;9(4):158-67.

74. Odudu A, Eldehni MT, McCann GP, Mclntyre CW. Randomized controlled trial of individualized dialysate cooling for cardiac protection in hemodialysis patients. Clin J Am Soc Nephrol. 2015;10(8):1408-17.

75. Higuchi T, Abe M, Yamazaki T, Okawa E, Ando H, Hotta S, et al. Levocarnitine improves cardiac function in hemodialysis patients with left ventricular hypertrophy: A randomized controlled trial. Am J Kidney Dis. 2016;67(2):260-70.

76. Liu J, Sun F, Ma LJ, Shen Y, Mei X, Zhou YL. Increasing dialysis sodium removal on arterial stiffness and left ventricular hypertrophy in hemodialysis patients. J Ren Nutr. 2016;26(1):38-44.

77. Lin C, Zhang Q, Zhang H, Lin A. Long-term effects of low-dose spironolactone on chronic dialysis patients: A randomized placebo-controlled study. J Clin Hypertens (Greenwich). 2016;18(2):121-8.

78. Jardine MJ, Zuo L, Gray NA, de Zoysa JR, Chan CT, Gallagher MP, et al. A trial of extending hemodialysis hours and quality of life. J Am Soc Nephrol. 2017;28(6):1898-911.

79. Miskulin DC, Gassman J, Schrader R, Gul A, Jhamb M, Ploth DW, et al. BP in dialysis: Results of a pilot study. J Am Soc Nephrol. 2018;29(1):307-16.

80. Charytan DM, Himmelfarb J, Ikizler TA, Raj DS, Hsu JY, Landis JR, et al. Safety and cardiovascular efficacy of spironolactone in dialysis-dependent ESRD (SPIN-D): A randomized, placebo-controlled, multiple dosage trial. Kidney Int. 2019;95(4):973-82.

81. Djuric P, Dimkovic N, Schlieper G, Djuric Z, Pantelic M, Mitrovic M, et al. Sodium thiosulphate and progression of vascular calcification in endstage renal disease patients: A double-blind, randomized, placebo-controlled study. Nephrol Dial Transplant. 2020;35(1):162-9.

82. Marshall MR, Vandal AC, de Zoysa JR, Gabriel RS, Haloob IA, Hood CJ, et al. Effect of low-sodium versus conventional sodium dialysate on left ventricular mass in home and self-care satellite facility hemodialysis patients: A randomized clinical trial. J Am Soc Nephrol. 2020;31(5):1078-91.

83. Edwards N, Price A, Mehta S, Hiemstra TF, Kaur A, Freasley PJ, et al. Effects of spironolactone and chlorthalidone on cardiovascular structure and function in chronic kidney disease. Clin J Am Soc Nephrol. 2021;16(10):1491-501.

84. Dorr K, Kammer M, Reindle-Schwaighofer R, Lorenz M, Prikoszovich T, Marculescu R, et al. Randomized trial of etelcalcetide for cardiac hypertrophy in hemodialysis. Circ Res. 2021;128:1616-25.

85. Fujii H, Kono K, Nakai K, Goto S, Nishii T, Kono A, et al. Effects of lanthanum carbonate on coronary artery calcification and cardiac abnormalities after initiating hemodialysis. Calcif Tissue Int. 2018;102:310-20.

86. Rutherford E, Ireland S, Mangion K, Stewart GA, MacGregor MS, Roditi $\mathrm{G}$, et al. A randomized, controlled trial of the effect of allopurinol on left ventricular mass index in hemodialysis patients. Kidney Int Rep. 2021;6:146-55.

87. Verma S, Mazer CD, Yan AT, Mason T, Garg V, Teoh H, et al. Effect of empagliflozin on left ventricular mass in patients with type 2 diabetes mellitus and coronary artery disease: The EMPA-Heart Cardiolink-6 randomized clinical trial. Circulation. 2019;140(21):1693-702.

88. Stenvinkel P, Carrero JJ, Axelsson J, Lindholm B, Heimbürger O, Massy Z. Emerging biomarkers for evaluating cardiovascular risk in the chronic kidney disease patient: How do new pieces fit into the uremic puzzle? Clin J Am Soc Nephrol. 2008;3(2):505-21.

89. Paoletti E, Bellino D, Gallina AM, Amidone M, Cassottana P, Cannella G. Is left ventricular hypertrophy a powerful predictor of progression to dialysis in chronic kidney disease? Nephrol Dial Transplant. 2011;26(2):670-7.

90. Park M, Hsu CY, Li Y, Mishra RK, Keane M, Rosas SE, et al. Associations between kidney function and subclinical cardiac abnormalities in CKD. J Am Soc Nephrol. 2012;23(10):1725-34

91. Hakeem A, Bhatti S, Dillie KS, Cook JR, Samad Z, Roth-Cline MD, et al. Predictive value of myocardial perfusion single-photon emission computed tomography and the impact of renal function on cardiac death. Circulation. 2008;118(24):2540-9.

92. Herzog CA, Shroff GR. Atherosclerotic versus nonatherosclerotic evaluation: The yin and yang of cardiovascular imaging in advanced chronic kidney disease. JACC Cardiovasc Imaging. 2014;7(7):729-32.

93. Herrington WG, Emberson J, Mihaylova B, Blackwell L, Reith C, Solbu $M D$, et al. Impact of renal function on the effects of $L D L$ cholesterol lowering with statin-based regimens: A meta-analysis of individual participant data from 28 randomised trials. Lancet Diabetes Endocrinol. 2016;4(10):829-39.

94. Sutton $M G$, Sharpe N. Left ventricular remodeling after myocardial infarction: Pathophysiology and therapy. Circulation. 2000;101(25):2981-8.

\section{Publisher's Note}

Springer Nature remains neutral with regard to jurisdictional claims in published maps and institutional affiliations.
Ready to submit your research? Choose BMC and benefit from:

- fast, convenient online submission

- thorough peer review by experienced researchers in your field

- rapid publication on acceptance

- support for research data, including large and complex data types

- gold Open Access which fosters wider collaboration and increased citations

- maximum visibility for your research: over 100M website views per year

At BMC, research is always in progress.

Learn more biomedcentral.com/submissions 